\title{
PROTECTING BUILT PROPERTY AGAINST FIRE DISASTERS: MULTI-ATTRIBUTE DECISION MAKING WITH RESPECT TO FIRE RISK
}

\author{
Egidijus Rytas VAIDOGAS ${ }^{1}$ and Jurgita ŠAKE்NAITÉ ${ }^{2}$ \\ ${ }^{1}$ Department of Occupational Safety and Fire Protection, Vilnius Gediminas Technical Uni- \\ versity, Sauletekio al. 11, LT-10223, Lithuania \\ E-mail: egidijus.vaidogas@vgtu.lt \\ ${ }^{2}$ Department of Occupational Safety and Fire Protection, Vilnius Gediminas Technical Uni- \\ versity, Sauletekio al. 11, LT-10223, Lithuania
}

Received 4 May 2010; accepted 12 July 2010

\begin{abstract}
The protection of buildings against fire disasters may require a comparison of alternative fire safety designs. The fire safety solutions can be compared by means of a general methodology known as multi-attribute selection or multi-criteria decision making. The alternative fire designs can be described by a number of attributes which characterise each of the alternatives. Fire risk expressed in the general form used for the quantitative risk assessment is applied to compose the set of attributes of a multi-attribute selection problem. It is shown how to accomplish the multi-attribute selection in the presence of epistemic uncertainties in the elements of fire risk estimate. Epistemic probability distributions assigned to elements of fire risk are specified and propagated though models of the multi-attribute selection by means of Monte Carlo simulation. An example presented in the paper considers the choice among alternative systems of automatic fire sprinklers.
\end{abstract}

KEYWORDS: Multiattribute decision making (MCDM); Fire; Sprinklers; Risk; Risk index

\section{INTRODUCTION}

It is needless to say that fire is the main physical hazard threatening life and property in non-industrial and many industrial buildings. Although some buildings involve the potentiality of other disastrous accidents, for instance, explosions of domestic gas, failure of structural and mechanical components (e.g., due to earthquake actions or component faults in elevators) or stampedes during a crown panic, fire remains the dominating cause of disasters in buildings. Fire in an individual building is a low-probability event; however, fires occur frequently and destroy life and property in a population of buildings in any country. A review of general statistics on fire damage in different countries is provided, among others, by Ramachandran (1998) and Yung (2008).

Fires in non-industrial buildings exhibit the same feature as many industrial accidents if we look at their consequences. A fire with minor, limited consequences is much more likely to happen in a particular building than a major fire disaster. A common feature in a number of disasters in buildings is a sudden spread of fire from apparently small fire to one which is highly threatening and disastrous. 
A review of fire disasters in public and office buildings is provided by Rasbash et al. (2004). Craighead (2009) describes major fires in highrise office buildings. Taking a look at these accidents allows to notice that a major fire is an uncertain and complex phenomenon influenced by many random processes and factors and capable to happen under various scenarios with different consequences. This turns building fires to an ideal subject of quantitative risk assessment (QRA) (Yung, 2008; Hasofer et al., 2007; Meacham, 2002; Hoła, 2006, 2007, 2009, 2010). However, the management of fire risk on the basis of QRA results remains an exception in dwellings, offices and public buildings. In Europe, QRA and QRA-based managerial decisions are mandatory only in nuclear power plants and industrial facilities regulated by the Seveso II directive (e.g., Kirchsteiger et al., 1998). In the US, the national fire protection organisations produced guidelines for fire risk assessment; however, the assessment itself is not mandatory practice in this country, to the best of our knowledge (SFPE, 2006; NFPA, 2009).

The present paper considers how to apply the results of fire risk estimation by means of QRA to a decision-making in the field of fire safety. The main idea is to incorporate results of QRA into the framework of the formal decision-making methodology known as multiattribute selection (MAS) or multi-criteria decision making (MCDM). It is shown that MAS will allow to compare alternative fire safety design by taking into account the fire risk associated with each of them.

\section{METHODOLOGICAL BACKGROUND}

\subsection{Performance-based fire codes and fire risk}

Although an application of QRA is possible, at least in principle, on the low level of decision-making (by building owners, insurers, manufacturers and constructors installing fire protection systems), the prevailing approaches to fire safety design is conforming to building regulations known as prescriptive fire codes and performance-based fire codes.

The practice of fire safety designs is changing from following traditional prescriptive design codes to more flexible performance-based codes (e.g., Natorianni, 2002). The fire designs in line with these two types of codes can be viewed as two principal attitudes to an application of risk assessment for fire safety provision.

The prescriptive codes are still widely used in many countries, including the authors' country Lithuania. The prescriptive design requirements generally relate to the provision of compartments with prescribed levels of fire resistance, the selection of building materials, the provision of escape facilities. The prescriptive requirements do not take sufficient account of the effectiveness of active fire protection measures such as sprinklers, ventilation systems and fire alarms. Prescriptive requirements, if enforced rigidly, can lead to costly over-design, particularly for some large and complex buildings (Ramachandran, 1998). The prescriptive design approach has been criticised by many publications for inability to provide the most cost-effective design solutions, to maintain a consistent level of fire safety in buildings, and, in general, for restricting innovation (Hasofer et al., 2007).

The performance-based codes allow flexibility in fire safety designs as long as the designs can provide the required level of fire safety to the occupants. The major objective of the performance-based design is to achieve satisfactory level of fire safety to the occupants and fire brigade personnel. Levels of fire safety (or, alternatively, fire risk) are assessed by applying risk assessment, either qualitative or quantitative (Guanquan and Jinhua, 2008; Yung, 2008; Hasofer et al., 2007). The latter is widely denoted by the acronym QRA intro- 
duced above. In other words, the performancebased approach is a risk-based one.

\subsection{Optimisation tasks in fire safety design}

The aim of performance-based fire design is, in essence, an optimisation task: to achieve the required level of fire safety (tolerable fire risk) by using minimum expenditures. The explicit use of fire risk measures opens up possibilities to apply formal methods of optimisation to decision-making concerning fire safety. The specific forms of optimisation problems depend on the level of a decision-maker. This level can range from a particular property owner to a state government (Ramachandran, 1998).

The optimisation problems related to firesafety design can be classified into two general types:

1. Determination of an optimum level of fire safety.

2. Search for an optimum combination of fire safety measures.

The determination of the optimum level of fire safety is expressed as a search for a fire protection strategy which yields the minimisation of total cost (Ramachandran, 2002). This task is based on classical problem of total cost minimisation (benefit maximisation) which is well known in the fields of reliability and risk management (e.g., Smith, 2005). The expression of the total cost includes the annual probability of fire occurrence; however, this problem is too "crude" because it doest not account for different fire scenarios which can end up in a variety consequences, direct and indirect ones.

The search for an optimum combination of fire safety measures can be formally expressed in the form of several problems of different generality:

a) The choice among alternative fire protection measures and their combinations using logical trees (e.g., a decision tree analysis) (e.g., Donegan, 2002); b) The search for an optimal package of fire protection and insurance (Ramachandran, 1998);

c) Cost-benefit evaluation of fire safety measures (Brown, 2005; Butry et al., 2007);

d) Search for a best configuration of an individual fire safety system (e.g., Lai et al., 2010).

The problems just listed are amenable to mathematical formalisation in the form of tasks of single- and multi-objective optimisation as well as the tasks of MAS. The distinction between the multi-objective optimisation and MAS can be viewed as a distinction between decision problems with continuous and discrete decision space (e.g., Sakalauskas and Zavadskas 2009; Zavadskas and Vaidogas, 2009).

The assessment of fire risk by means of QRA results in a discrete set of estimates (likelihood-outcome pairs). Therefore, the main result of QRA, the expression of risk, can be embedded into a MAS problem with relative ease. We think that the "marriage" of QRA and MAS can allow to make fire safety related decisions which implements the goals of performance-based and are based on formal tools of MAS.

\section{MULTI-ATTRIBUTE SELECTION IN RISK-BASED FIRE SAFETY DESIGN}

\subsection{MAS problem and fire safety aspects}

The MAS aims at determining the best alternative $a^{*}$ or a subset of leading alternatives among a discrete set of alternatives represented by the vector $\boldsymbol{a}=\left(a_{1}, a_{2}, \ldots, a_{i}, \ldots, a_{m}\right)^{\mathrm{T}}$. The quality of $a_{i}$ is evaluated by means of a row-vector $\boldsymbol{c}_{i}=\left(c_{i 1}, c_{i 2}, \ldots, c_{i j}, \ldots, c_{i n}\right)$, the components of which, $c_{i j}$, are attributes of $a_{i}$ (or criteria) used for MAS. In terms of MAS, the element $c_{i j}$ expresses impact of the $i$ th alternative on the $j$ th attribute. 
Data for solving a MAS problem is formulated as a $m \times n$ decision matrix:

$$
\mathbf{C}=\left[\boldsymbol{c}_{1}, \ldots, \boldsymbol{c}_{i}, \ldots, \boldsymbol{c}_{m}\right]^{\mathrm{T}}
$$

The values $c_{i j}$ making up different columns of $\mathbf{C}$ are usually of different units. To facilitate inter-attribute comparisons, the components $c_{i j}$ are normalised. A normalised (dimensionless) decision matrix $\overline{\mathbf{C}}$ is obtained from $\mathbf{C}$. The structure of $\overline{\mathbf{C}}$ is:

$$
\overline{\mathbf{C}}=\left[\overline{\boldsymbol{c}}_{1}, \ldots, \overline{\boldsymbol{c}}_{i}, \ldots, \overline{\boldsymbol{c}}_{m}\right]^{\mathrm{T}}
$$

where: $\overline{\boldsymbol{c}}_{i}=\left(\bar{c}_{i 1}, \bar{c}_{i 2}, \ldots, \bar{c}_{i j}, \ldots, \bar{c}_{i n}\right) \quad(i=1,2, \ldots$, $m$ ) is the row-vector calculated by normalizing components of the corresponding $\boldsymbol{c}_{i}$. Most methods of MAS select $a^{*}$ with the normalised $\overline{\mathbf{C}}$ and not the initial $\mathbf{C}$ (Triantaphyllou, 2000; Hwang and Yoon, 1981). Examples of normalization formulas used to obtain $\bar{c}_{i j}$ from $c_{i j}$ are given by Vaidogas (2007), Vaidogas and Hayashi (2007), Liu (2009), Peldschus (2009), Urbanavičienė et al. (2009), Zavadskas et al. (2008).

The difference in significance of the attributes $c_{i j}(i=1,2, \ldots, m)$ is expressed by the vector of weights, $\boldsymbol{w}=\left(w_{1}, w_{2}, \ldots, w_{j}, \ldots, w_{n}\right)^{\mathrm{T}}$. Usually, the weights $w_{j}$ are between 0 and 1 and add up to 1 . If $\boldsymbol{w}$ is applied, the search for $a^{*}$ is carried out by using the attribute values $w_{j} \bar{c}_{i j}$. A number of formal methods are suggested in the literature for specifying $w_{j}$, both crisp and fuzzy (Hwang and Yoon, 1981; Triantaphyllou, 2000). These methods can be as informal as Delphi method or as formal as the eigenvector technique of the analytical hierarchy process (e.g., Donegan, 2002). An example of specifying $w_{j}$ used for fire related decisions in the Edinburgh method developed for ranking fire safety attributes of buildings (Watts, 2002; Rasbash et al., 2004).

The key element of each MAS method is the criterion, according to which $a_{i}$ are ranked and the best one, $a^{*}$, is selected (MAS criterion, in short). In this paper, criteria of several, say, $n_{k}$ methods applied to selecting $a^{*}$ will be denoted by the letters $K_{1}, K_{2}, \ldots, K_{k}, \ldots, K_{n_{k}}$. The buoyant literature devoted to the development and comparison of the criteria $K_{k}$ is conveniently reviewed by French (1988), Triantaphyllou (2000), Figueira et al. (2005).

Applications of MAS criteria $K_{k}$ to realworld problems are numerous and found in very different fields. In the field of fire safety, these criteria were applied mainly to ranking fire safety attributes (Rasbash et al., 2004; Zhao et al., 2004; Hoła and Schabowicz, 2010; Schabowicz and Hola, 2007).

The specification of $\boldsymbol{w}$, and the choice of $K_{k}$, together with the calculation of $\overline{\mathbf{C}}$ require to make subjective decisions. For instance, different MAS methods should be chosen for different decision-making situations by answering subjective questions (Hwang and Yoon, 1981). The subjectivity of MAS is a natural background for applying uncertain attributes $c_{i j}$. Uncertainty distributions widely used in QRA and expressing, in essence, a subjective degree of belief naturally match the subjective setting of MAS.

\subsection{Alternative fire designs}

In context of the fire design, the alternatives $a_{i}$ can be alternative fire safety designs:

1. To install some fire protection measure(s) in a building or to retain it without any protection;

2. To install only one specific protection measure or a combination of measures, for instance, sprinklers or automatic detectors alone, or both sprinklers and detectors;

3. To choose among several types of a specific safety measure, for example, among several sprinkler types (dry-pipe sprinklers, wet-pipe sprinkles, etc.);

4. To choose among several producers (importers) of specific equipment used as a fire protection measure;

5. To choose among more complicated alternatives which can include specific 
combinations of fire protection measures as well as the alternative of "doing nothing" (not installing any fire protection if this is allowed by regulations).

The alternative fire safety designs listed above are related to active fire protection measures. However, alternative solutions can also be generated by considering also passive fire protection, such as alternative compartmentalisation or choosing among alternative walls, doors, structural members.

Alternative solutions of active and passive fire protection are amenable to a formal comparison within an MAS problem. Economic attributes and attributes expressing standard technical characteristics of fire protection measures can be a natural part of this problem. However, the MAS problem should also include attributes which directly or indirectly express risk posed by potential fire. Fire protective measures are installed to reduce this risk and eventually their effectiveness should be measured in terms of risk reduction.

\subsection{MAS attributes related to fire safety}

The alternative solutions of active and passive fire protection can be compared within the decision tree analysis, in which they are called "safety strategies" or "courses of action" (Rasbash et al., 2004; Donegan, 2002; Ramachandran, 1998). The decision tree is the appropriate approach to use if the object is to identify the alternative $a_{i}$ optimising a single attribute, say, $c_{i 1}$ (e.g., the most cost effective fire protection strategy identified by searching for minimum total annual cost). Thus the decision tree analysis can be considered a special, simplified case of MAS. However, the complexity of fire safety evaluation problems may require to compare the alternatives $a_{i}$ by means of more than a single attribute $c_{i 1}$.

In our opinion, the attributes $c_{i j}$ evaluating the alternatives $a_{i}$ can be grouped into four categories:
I. Attributes expressing technical characteristics of fire safety measures (performance, effectiveness, reliability (availability), e.g., see the chapter 10 in Rasbash et al. (2004) for a description of such attributes).

II. Economic (monetary) attributes of fire protection measures (life-cycle cost or costs specified on a detailed level: initial budget cost, maintenance cost, etc.; an example of life-cycle costing of a fire protection measure (sprinklers) is provided by Brown (2005).

III. Attributes expressing different attitudes towards insurance against fire (e.g., see chapters 6 and 11 in Ramachandran (1998) for a description of fire insurance).

IV. Safety-related attributes expressing influence of individual alternative design $a_{i}$ on the risk to life and property. As failures of fire protection measures in the course of fire can lead to severe escalation of accident, the attribute "reliability" mentioned in the first group can be included in this category.

Attributes of the categories I and II are of general nature and are applicable, in principle, to any building system. Finding the values for most of the attributes belonging to these categories shouldn't be a difficult exercise. The exception is the attribute "reliability". An estimation of reliability (demand availability) of such systems as automatic sprinklers, fire detectors, ventilation systems, smoke ventilators and fire doors can be a non-trivial task which must be solved by applying special methods of QRA (e.g., Hauptmanns et al., 2008).

The insurance-related attributes of the category III can be assigned, formally, to the economic category II as insurance premiums are simple monetary quantities. However, it makes sense to exclude them into a separate category because finding values of these attributes can be a difficult exercise, especially when MAS is to be applied in the early stages of the design 
(prior to negotiations with individual insurers). In addition, insurance premiums can depend on the current economic situation in the insurance industry and only partially on the fire risk level of a building to be insured (see, e.g. Watts, 2002) for fire risk indices used by insurers). In addition, insurers use their own indices of fire risk which substantially differ from the indices measures prevailing among fire safety engineers (Watts, 2002). If necessary, the insurers' indices can be incorporated into an MAS problem.

Attributes of the category IV relate a specific alternative design $a_{i}$ to the level of fire safety (or, alternatively, fire risk) of the building which can be achieved by means of $a_{i}$. It is natural to state that the effectiveness of $a_{i}$ should be measured eventually by this level.

The following two approaches to quantifying fire risk of entire building are well-known in the field of fire safety:

- Fire risk indexing (e.g., Rasbash et al., 2004; Watts, 2002);

- Fire risk assessment carried out in line with QRA (see the references given in Introduction).

The two approaches can be viewed as methodological tools of the performance-based fire design. The difference between fire risk indexing and fire risk assessment resembles difference between traditional deterministic structural analysis and reliability-based one (Šakènaitè and Vaidogas, 2010).

A fire risk index, say, $I\left(\boldsymbol{x}_{i}\right)$ fits naturally for a MAS attribute $c_{i j}$, that is, $c_{i j} \equiv I\left(\boldsymbol{x}_{i}\right)$. Most of the widely-known indices are calculated with relative ease as functions of a relatively large number of building characteristics relevant to fire safety (components of the vector $\boldsymbol{x}_{i}$ ). The characteristics are called "fire safety parameters or attributes", albeit the term "attribute" is not used in the sense of MAS (Rasbash et al., 2004; Watts and Solomon, 2002; Watts and Kaplan, 2001).
Almost all fire risk indices are calculated as single (scalar) values and pretend to covering all fire consequences. The FRAME fire index is calculated in the form of three values, say, $I_{1}\left(\boldsymbol{x}_{i}\right), I_{2}\left(\boldsymbol{x}_{i}\right)$ and $I_{3}\left(\boldsymbol{x}_{i}\right)$ which express fire risk to building and its content, occupants and business activities, respectively (FRAME, 2010). The distinguishing between different kinds of fire consequences makes the FRAME index closer to the expression of risk used for QRA. The FRAME index can be incorporated into MAS problem in the form of three separate attributes, for instance, $\left.c_{i j} \equiv I_{1}\left(\boldsymbol{x}_{i}\right), c_{i, j+1} \equiv I_{2}\left(\boldsymbol{x}_{i}\right)\right)$ and $c_{i, j+2} \equiv I_{3}\left(\boldsymbol{x}_{i}\right)$.

Although fire risk indices $I\left(\boldsymbol{x}_{i}\right)$ are natural candidates to be used as MAS attributes $c_{i j}$, their use in the framework of MAS can be problematic due to a possible insufficient sensitivity to the differences presented by the alternative designs $a_{i}$. The indices may not have input variables (components of $\boldsymbol{x}_{i}$ ) which allow to distinguish between different types of fire protection measures, for instance, different types of sprinklers or sprinklers systems of the same type but with different level of reliability.

A systematic investigation of the indices $I\left(\boldsymbol{x}_{i}\right)$ differences in fire safety measures expressed in our case by the alternatives $a_{i}$ is not known to us. Our finding is that the widely-known indices are either incapable or too rough to express subtle differences among fire safety measures represented by $a_{i}$ (Šakènaitè and Vaidogas, 2010).

Other problems with the use of indices are not MAS specific ones; however, these problems may reduce attractiveness of the indices $I\left(\boldsymbol{x}_{i}\right)$ to the use within MAS:

a) The indices $I\left(\boldsymbol{x}_{i}\right)$ are fairly different systems used to quantify fire risk; it is difficult to compare results produced by different indices;

b) Different indices are used in different countries and their use seems to be a result of agreement between interested 
parties in a specific country rather than a result of some scientific reasoning;

c) Some of the indices are applicable to wide range of buildings; whereas some are applied to highly specific buildings and other kind of property;

d) Algorithms used to calculate the indices $I\left(\boldsymbol{x}_{i}\right)$ and input information possess high degree subjectivity; a specification of this information is not well documented;

e) The indices $I\left(\boldsymbol{x}_{i}\right)$ are generally "rigid" systems; they do not allow to take account of new developments in fire risk assessment.

We think that the listed shortcomings of the fire risk indices $I\left(\boldsymbol{x}_{i}\right)$ may limit their application to MAS. An alternative approach to fire risk indexing is a fire risk assessment in line with QRA. Results of QRA can be serve as MAS attributes related to fire safety.

\section{INCORPORATING FIRE RISK MEASURES INTO MAS}

\subsection{Fire risk in decision matrix}

A very comprehensive attribute of the alternative fire designs $a_{i}$ is the risk defined in line with QRA, i.e. in the form of likelihood-outcome pairs (Yung, 2008; Hasofer et al., 2007). In the context of this paper, the risk of $a_{i}$ due to exposure to a potential fire will consist of possible outcomes (consequences) $o_{i r}$ of this situation and likelihoods $l_{i r}$ of $o_{i r}$. Generally, each $o_{i r}$ is represented by several measures of significance or, in brief, significances (Kumamoto and Henley, 1996). Each $o_{i r}$ can be characterised by several, say, $n$ significances of a different nature and with different measurement units. The significances can be grouped into the row-vector:

$$
\boldsymbol{s}_{i r}=\left(s_{i r 1}, s_{i r 2}, \ldots, s_{i r j}, \ldots, s_{i r n}\right)
$$

With the values $l_{i r}, o_{i r}, \boldsymbol{s}_{i r}$, the fire risk related to $a_{i}$ takes the following form:

Fire risk related to $a_{i} \equiv$

$$
\left\{\left(l_{i r}, o_{i r}, \boldsymbol{s}_{i r}\right), r=1,2, \ldots, n_{i}\right\}
$$

The alternatives $a_{i}$ with different level of risk can be generated by comparing the fire designs with different probabilities of failure (success) given a fire. This will require to estimate failure probabilities of alternative automatic sprinkler systems and fire detection and alarm systems. Methods and data used for such an estimation are considered, among others, by Hall (2010), Hauptmanns et al. (2008), Nyyssönen et al. (2005), Rönty et al. (2004), Vaidogas (2003, 2006). In many cases the estimation of the failure probabilities will be a non-trivial task. Potential points of introduction of the alternative fire designs with different failure probabilities are shown in Figure 1.

The total number of the outcomes, $n_{i}$, may vary from alternative to alternative. The risk (4) may express fairly diverse information, especially when the severity of each $o_{i r}$ is represented by more than one significance measure. The vectors $\boldsymbol{s}_{i r}\left(r=1,2, \ldots, n_{i}\right)$ can be grouped in the $n_{i} \times n$ matrix:

$$
\left[\boldsymbol{s}_{i 1}, \boldsymbol{s}_{i 2}, \ldots, \boldsymbol{s}_{i r}, \ldots, \boldsymbol{s}_{i n_{i}}\right]^{\mathrm{T}}
$$

Each column of the above matrix consists of significances with the same measurement unit. With this matrix, one can calculate $n$-dimensional vector of expected significances that are associated with $i$ th alternative and apply this vector within MAS, namely,

$$
\begin{gathered}
\boldsymbol{c}_{i}=\left(\sum_{r=1}^{n_{i}} l_{i r} s_{i r 1}, \sum_{r=1}^{n_{i}} l_{r_{i}} s_{i r 2}, \ldots\right. \\
\left.\ldots, \sum_{r=1}^{n_{i}} l_{i r} s_{i r j}, \ldots, \sum_{r=1}^{n_{i}} l_{i r} s_{i r n}\right)
\end{gathered}
$$




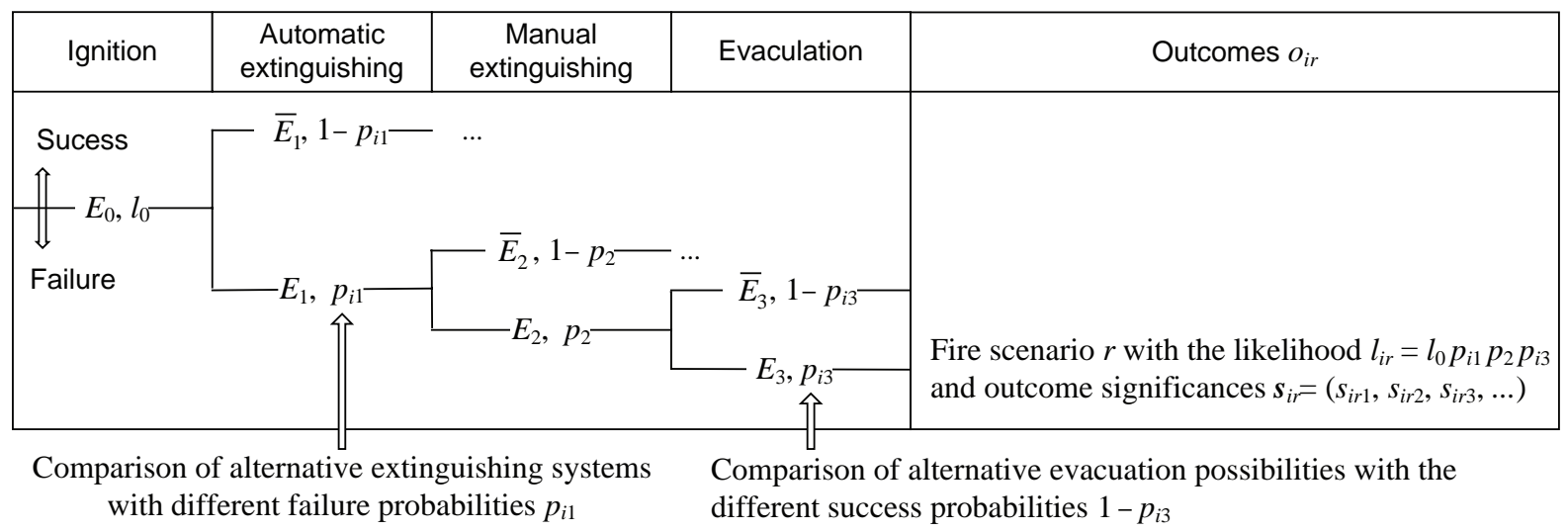

Figure 1. A fragment of an event tree diagram with the event tree path expressing the fire scenario $r$; the diagram shows also potential points of consideration of alternative fire design solutions within a QRA problem

In the case that the severity of each $o_{i r}$ is represented by a single significance $s_{i r}$ (vectors $\boldsymbol{s}_{i r}$ consist of a single component), the expected significance $\sum_{r=1}^{n_{i}} l_{i r} s_{i r j}$ will be a scalar value and comparison of $a_{i}$ will be straightforward, provided that further attributes are not introduced into the MAS problem.

The expected significances in Eq. (6) contain the likelihoods $l_{i r}$, which in many cases can be estimated independently of the significances $s_{i r j}$ (e.g., Kumamoto and Henley, 1996). Each $l_{i r}$ can be expressed as probability of $o_{i r}$ per fire. Frequencies (numbers of occurrences per year) are also used as $l_{i r}$.

If $l_{i r}$ is associated with $r$ th event tree path consisting of $n_{b r}$ branching points, $l_{i r}$ is calculated as $l_{i r}=l_{0} \prod_{b=1}^{n_{b r}} p_{b}^{\prime}$, where $l_{0}$ and $p_{b}^{\prime}$ is the likelihood of an initiating event $E_{0}$ and the probability of $b$ th branching point represented by an event pair $E_{b}$ and $\bar{E}_{b}$, respectively (e.g., the event tree diagram in Figure 1 shows that $l_{i r}=l_{0} p_{1}^{\prime} p_{2}^{\prime} p_{3}^{\prime}$ and $\left.n_{b r}=3\right)$.

\subsection{The need to deal with uncertainties}

The prevailing method of uncertainty quantification in QRA is the classical Bayesian approach to QRA (Bayesian approach). In line with the Bayesian approach, the uncertainty in parameters and input of QRA models is divided into aleatory (stochastic) and epistemic (state-of-knowledge) uncertainty (e.g., Vaidogas 2009; Vaidogas and Juocevičius, 2008a, 2009; Helton and Oberkampf, 2004; Aven and Pörn, 1998). This division is used due to the sparseness of data related to QRA models and for the convenience of modelling. The Bayesian approach produces estimates of risk and failure probabilities expressed in terms of epistemic uncertainty distributions. An incorporation of these distributions into MAS requires selecting $a^{*}$ in the presence of uncertain components $c_{i j}$ of $\mathbf{C}$.

In the context of the Bayesian approach, $l_{\text {ir }}$ will be estimated in the form of epistemic uncertainty distributions related to true, albeit unknown values of $l_{i r}$. Such estimations are usually carried out by propagating epistemic uncertainties through such QRA models as event trees and fault trees (e.g., Figure 3) (Aven and Pörn, 1998; Vaurio and Jänkälä, 2006; Vaidogas and Juocevičius 2007, 2008b). Fire-specific applications of the separate modelling of aleatory and epistemic uncertainties were suggested in previous decades by Siu and Apostolakis (1988) and Bradyberry and Apostolakis (1991). 
In the context of the Bayesian approach, $l_{0}$ and the branching probabilities $p_{b}^{\prime}(b=1,2, \ldots$, $n_{b r}$ ) may be uncertain in the epistemic sense. Such an uncertainty can be quantified by the respective random variables $L_{0}$ and $\tilde{p}_{b}^{\prime}$. Then the epistemic uncertainty in the likelihoods $l_{\text {ir }}$ can be expressed by the random variable $L_{i r}=L_{0} \prod_{b=1}^{n_{b r}} \tilde{p}_{b}^{\prime}$. With the random likelihoods $L_{i r}\left(r=1,2, \ldots, n_{i}\right)$, the expected significance $\sum_{r=1}^{n_{i}} l_{i r} s_{i r j}$ turns into the epistemic random variable $\tilde{c}_{i j}=\sum_{r=1}^{n_{i}} L_{i r} s_{i r j}$. This replacement yields a MAS problem with stochastic attribute vectors:

$$
\tilde{\boldsymbol{c}}_{i}=\left(\tilde{c}_{i 1}, \tilde{c}_{i 2}, \ldots, \tilde{c}_{i j}, \ldots, \tilde{c}_{i n}\right)
$$

Replacing $\boldsymbol{c}_{i}$ in the initial deterministic decision matrix $\mathbf{C}$ by $\tilde{\mathrm{c}}_{i}$ defined by either Eq. (1) will yield a stochastic decision matrix:

$$
\tilde{\mathbf{C}}=\left[\tilde{\mathrm{c}}_{1}, \ldots, \tilde{\mathrm{c}}_{i}, \ldots, \tilde{\mathrm{c}}_{m}\right]^{\mathrm{T}}
$$

The uncertainties expressed by elements of $\tilde{\mathbf{C}}$ may not necessarily be epistemic ones. Apart from the epistemic random variables $\sum_{r=1}^{n_{i}} L_{i r} s_{i r j}$, the matrix $\tilde{\mathbf{C}}$ may contain elements that are uncertain in the aleatory sense.

The MAS problem formulated in the form of $\tilde{\mathbf{C}}$ can be solved by applying the propagation of epistemic and, if necessary, aleatory uncertainties (Zavadskas and Vaidogas; 2009). The solution will consists in sampling values $\tilde{\mathbf{C}}_{l}$ of $\tilde{\mathbf{C}}$ by means of Monte Carlo simulation $\left(l=1,2, \ldots, N_{l}\right)$. The MAS problem can be solved and the best alternative can be chosen for each $\tilde{\mathbf{C}}_{l}$. The simulation will yield the frequencies of the selection of individual alternatives $a_{i}$ as the best ones in $N_{l}$ trials. Then the alternative with the highest frequency of selection can be chosen as $a^{*}$.

\section{APPLICATION EXAMPLE}

A sprinkler system among three alternative systems $a_{1}, a_{2}$, and $a_{3}$ is to be chosen. The alternatives $a_{1}, a_{2}$, and $a_{3}$ denote dry pipe, deluge and pre-action sprinklers, respectively (Table 1). The most appropriate one, $a^{*}$, will serve along with automatic fire detectors and alarm system as fire protection measure in an industrial building. A potential fire accident in this building has four possible scenarios represented by the event tree given in Figure 2 .

Table 1. Initial data used for the selection from

\begin{tabular}{|c|c|}
\hline System & Fire likelihood $l_{0}\left(\right.$ year $\left.^{-1}\right)$ \\
\hline \multirow[t]{2}{*}{$\begin{array}{l}\text { All systems } \\
a_{1}, a_{2}, a_{3}\end{array}$} & $\begin{array}{l}L_{0} \sim \mathrm{G}(3,20) \text { (a gamma distribution } \\
\text { with the mode of } 0,10 \text { ) }\end{array}$ \\
\hline & Alarm failure probability $p_{\mathrm{f} 1}$ \\
\hline \multirow{2}{*}{$\begin{array}{l}\text { All systems } \\
a_{1}, a_{2}, a_{3}\end{array}$} & $\tilde{p}_{1} \sim \operatorname{Be}(4,58)$ with the mode of 0,05 \\
\hline & Sprinkler failure probability $p_{\text {fi } 2}$ \\
\hline Dry pipe $a_{1}$ & $\tilde{p}_{12} \sim \operatorname{Be}(4 ; 55)$ (beta distribution) \\
\hline Deluge $a_{2}$ & $\tilde{p}_{22} \sim \operatorname{Be}(4 ; 60)$ \\
\hline \multirow[t]{2}{*}{ Pre-action $a_{3}$} & $\tilde{p}_{32} \sim \operatorname{Be}(3 ; 30)$ \\
\hline & Mode of the distribution of $p_{f i 2}$ \\
\hline Dry pipe $a_{1}$ & 0.0526 \\
\hline Deluge $a_{2}$ & 0.0484 \\
\hline \multirow[t]{2}{*}{ Pre-action $a_{3}$} & 0.0645 \\
\hline & Cost $c_{i 5}$ of $a_{i}(€ m l n)$ \\
\hline Dry pipe $a_{1}$ & $c_{15}=0.30$ \\
\hline Deluge $a_{2}$ & $c_{25}=0.24$ \\
\hline Pre-action $a_{3}$ & $c_{35}=0.27$ \\
\hline
\end{tabular}
alternative sprinkler systems

The structure of the event tree diagram is identical for all three sprinkler systems $a_{1}, a_{2}$, and $a_{3}$. The fire risk related to the sprinklered building is given by:

$$
\operatorname{Risk}_{i} \equiv\left\{\left(l_{i r}, o_{i r}, \boldsymbol{s}_{i r}\right), r=1,2,3,4\right\}
$$

where: the index $i$ refers to the alternative $a_{i}$ $(i=1,2,3) ; l_{i r}$ is the likelihood of the scenario $r$ with the outcome $o_{i r}$ in the building with sprinklers $a_{i}$; and $\boldsymbol{s}_{i r}$ is the vector of significances of $o_{i r}$. 


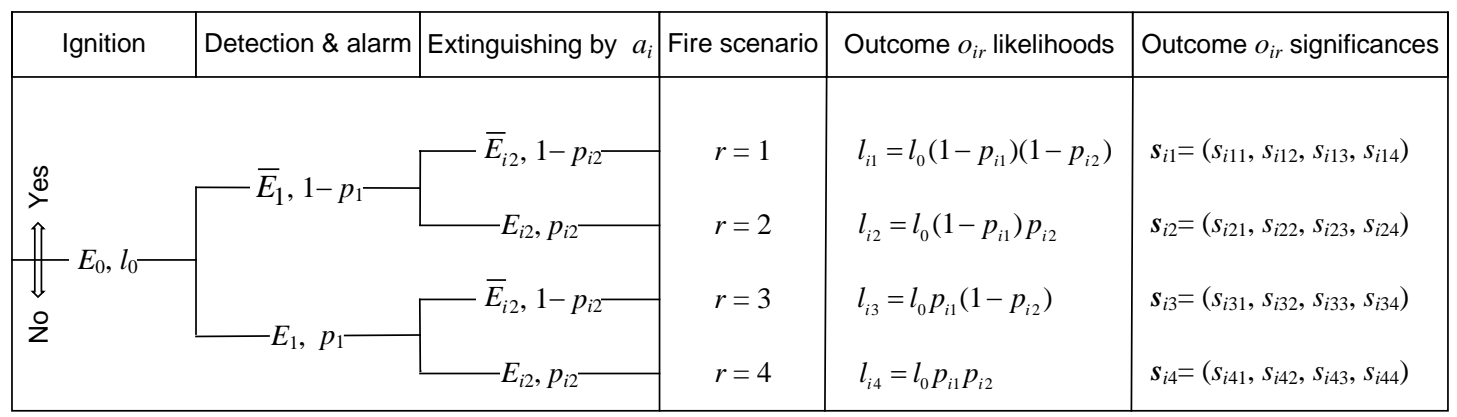

Figure 2. Simplified event tree diagram for a fire in a sprinklered building with a fire detection and alarm system

As shown in Figure 2, the vectors $\mathrm{s}_{i r}$ are expressed as $\boldsymbol{s}_{i r}=\left(\mathrm{s}_{i r 1}, \mathrm{~s}_{i r 2}, \mathrm{~s}_{i r 3}, \mathrm{~s}_{i r 4}\right)$, where $\mathrm{s}_{i r 1}$ is the property loss due to fire and/or fire suppression (€th.); $\mathrm{s}_{i r 2}$ is the number of possible deaths among workers; $\mathrm{s}_{i r 3}$ is the possible number of injured workers; and $s_{i r 4}$ is the outage of the industrial building in consequence of the fire (days).

The likelihood $l_{i r}$ must be estimated from the following quantities:

- The likelihood of ignition (initiating event) $E_{0}, l_{0}$;

- The conditional probability of alarm failure, $p_{1}=P\left(E_{1} \mid E_{0}\right)$; and

- The conditional probabilities that sprinklers $a_{i}$ will fail given $E_{0} \cap E_{1}$ or $E_{0} \cap \bar{E}_{1}$, namely, $p_{i 2}=P\left(E_{i 2} \mid E_{0} \cap E_{1}\right)$ (Figure 2).

The expression of the risk given by Eq. (9) will be used to form the attribute vector $\boldsymbol{c}_{i}=\left(c_{i 1}, c_{i 2}, c_{i 3}, c_{i 4}, c_{i 5}\right)$, in which $c_{i 1}$ to $c_{i 4}$ are expected significances treated later as random variables and $c_{i 5}$ will be the fixed (deterministic) cost of $a_{i}(€ m l n)$ (the values of $c_{i 5}$ are given in Table 1).

The fire $E_{0}$ in a specific building is generally a rare and difficult-to-predict event and so are the failures of alarm and sprinklers, $E_{1}$ and $E_{i 2}$, given $E_{0}$. Therefore $l_{0}, p_{1}$, and $p_{i 2}$ can be uncertain in the epistemic sense (e.g., Bradyberry and Apostolakis, 1991). In the present example, the uncertainty in $l_{0}, p_{1}$, and $p_{i 2}$ is quantified by respective epistemic random variables $L_{0}, \tilde{p}_{1}$, and $\tilde{p}_{i 2}$ with the hypothetical probability distributions specified in Table 1 (the definition of the QRA term "epistemic uncertainty" is given, for instance, by Aven, 2003).

The epistemic uncertainty in the likelihoods $l_{i r}$ is modelled by the random variables $L_{i r}$ expressed through the epistemic random variables defined in Table 1:

$$
\begin{aligned}
& L_{i 1}=L_{0}\left(1-\tilde{p}_{1}\right)\left(1-\tilde{p}_{i 2}\right) \\
& L_{i 2}=L_{0}\left(1-\tilde{p}_{1}\right) \tilde{p}_{i 2} \\
& L_{i 3}=L_{0} \tilde{p}_{1}\left(1-\tilde{p}_{i 2}\right) \\
& L_{i 4}=L_{0} \tilde{p}_{1} \tilde{p}_{i 2}
\end{aligned}
$$

Components of the vectors $\mathrm{s}_{i r}$ are assumed to be random variables and denoted by the symbols $\tilde{s}_{i r 1}, \quad \tilde{s}_{i r 2}, \quad \tilde{s}_{i r 3}$ and $\tilde{s}_{i r 4}$. They are grouped to a random vector $\tilde{\boldsymbol{s}}_{i r}=\left(\tilde{s}_{i r 1}, \tilde{s}_{i r 2}, \tilde{s}_{i r 3}\right.$, $\left.\tilde{s}_{i r 4}\right)$. The property loss due to fire, $\tilde{s}_{i r 1}$, obeys a lognormal distribution (Rasbash et al., 2004). The parameters $\mu_{i r}$ and $\sigma_{i r}$ of the random variable $\tilde{s}_{i r 1} \sim L\left(\mu_{i r}, \sigma_{i r}\right)$ are given in Table 2. The values of $\mu_{i r}$ and $\sigma_{i r}$ were calculated by using mean values of $\tilde{s}_{i r 1}$ obtained from the statistics of fires in industry (Ramachandran, 1998). 
Table 2. Components of the random significance vectors $\tilde{\mathrm{s}}_{i r}{ }^{*}$

\begin{tabular}{|c|c|c|c|c|c|}
\hline \multicolumn{6}{|c|}{ Dry pipe system $a_{1}$} \\
\hline \multicolumn{5}{|c|}{ Vectors $\tilde{\boldsymbol{s}}_{1 r}(\mathrm{i}=1 ; \mathrm{r}=1,2,3,4)$} & \multirow{5}{*}{$\begin{array}{l}\text { The mean } \mu_{\text {ir }} \text { and std. dev. } \sigma_{\text {ir }} \text { of } \tilde{s}_{i r 1} \text { (€th) } \\
\tilde{s}_{111}: \mu_{11}=1.5, \sigma_{11}=0.3 \\
\tilde{s}_{121}: \mu_{12}=5.3, \sigma_{12}=1.325 \\
\tilde{s}_{131}: \mu_{13}=1.5, \sigma_{13}=0.3 \\
\tilde{s}_{141}: \mu_{14}=6.1, \sigma_{14}=1.525\end{array}$} \\
\hline$\left[\tilde{\boldsymbol{s}}_{11}\right]$ & {$[L(0.348,0.198)$} & 0 & $B(20,0.01)$ & $P(2.0)$ & \\
\hline$\tilde{\boldsymbol{s}}_{12}$ & $L(1.637,0.246)$ & $B(20,0.10)$ & $B(20,0.30)$ & $P(17.0)$ & \\
\hline$\tilde{\boldsymbol{s}}_{13}$ & $L(0.348,0.198)$ & $B(20,0.05)$ & $B(20,0.15)$ & $P(2.0)$ & \\
\hline$\left[\tilde{s}_{14}\right\rfloor$ & $L(1.778,0.246)$ & $B(20,0.25)$ & $B(20,0.45)$ & $P(19.0)$ & \\
\hline \multicolumn{6}{|c|}{ Deluge system $a_{2}$} \\
\hline \multicolumn{5}{|c|}{ Vectors $\tilde{\boldsymbol{s}}_{2 r}(\mathrm{i}=2 ; \mathrm{r}=1,2,3,4)$} & The mean $\mu_{i r}$ and std. dev. $\sigma_{i r}$ of $\tilde{s}_{i r 1}(€$ th) \\
\hline$\left[\tilde{\boldsymbol{s}}_{21}\right]$ & $\lceil L(1.013,0.601)$ & 0 & $B(20,0.01)$ & $P(4.0)$ & $\tilde{s}_{211}: \mu_{21}=3.3, \sigma_{21}=0.66$ \\
\hline$\tilde{\boldsymbol{s}}_{22}$ & $L(1.637,0.246)$ & $B(20,0.10)$ & $B(20,0.30)$ & $P(17.0)$ & $\tilde{s}_{221}: \mu_{22}=5.3, \sigma_{22}=1.325$ \\
\hline$\tilde{\boldsymbol{s}}_{23}$ & $L(1.013,0.601)$ & 0 & $B(20,0.05)$ & $P(4.0)$ & $\tilde{s}_{231}: \mu_{23}=3.3, \sigma_{23}=0.66$ \\
\hline$\tilde{s}_{24}$ & $L(1.778,0.246)$ & $B(20,0.25)$ & $B(20,0.45)$ & $P(19.0)$ & $\tilde{s}_{241}: \mu_{24}=6.1, \sigma_{24}=1.525$ \\
\hline \multicolumn{6}{|c|}{ Pre-action system $\alpha_{3}$} \\
\hline \multicolumn{5}{|c|}{ Vectors $\tilde{\boldsymbol{s}}_{3 r}(\mathrm{i}=3 ; \mathrm{r}=1,2,3,4)$} & The mean $\mu_{i r}$ and std. dev. $\sigma_{i r}$ of $\tilde{s}_{i r 1}$ (€th) \\
\hline$\left[\tilde{\boldsymbol{s}}_{31}\right]$ & $\lceil L(0.475,0.331)$ & 0 & $B(20,0.01)$ & $P(2.0)$ & $\tilde{s}_{311}: \mu_{31}=1.7, \sigma_{31}=0.34$ \\
\hline$\tilde{\boldsymbol{s}}_{32}$ & $L(1.637,0.246)$ & $B(20,0.10)$ & $B(20,0.30)$ & $P(17.0)$ & $\tilde{s}_{321}: \mu_{32}=5.3, \sigma_{32}=1.325$ \\
\hline$\tilde{\boldsymbol{s}}_{33}$ & $L(0.475,0.331)$ & $B(20,0.05)$ & $B(20,0.15)$ & $P(2.0)$ & $\tilde{s}_{331}: \mu_{33}=1.7, \sigma_{33}=0.34$ \\
\hline$\left[\tilde{\boldsymbol{s}}_{34}\right.$ & $L(1.778,0.246)$ & $B(20,0.25)$ & $B(20,0.45)$ & $P(19.0)$ & $\tilde{s}_{341}: \mu_{34}=6.1, \sigma_{34}=1.525$ \\
\hline
\end{tabular}

*The probability distributions and their parameters presented in the table are hypothetical; $L(\cdot), B(\cdot)$ and $P(\cdot)$ denotes lognormal, binomial and Poisson distribution, respectively

Values of standard deviations of $\tilde{s}_{i r 1}$ given in Table 2 were assumed hypothetically.

The number of employees in the building under analysis is assumed to be fixed and equal to 20. The numbers of victims (fatalities and injuries), to the contrary, are modelled by random variables $\tilde{s}_{i r 2}$ and $\tilde{s}_{i r 3}$ which obey a binomial distribution, that is, $\tilde{s}_{i r 2} \sim B\left(20, \phi_{i r 2}\right)$ and $\tilde{s}_{i r 3} \sim B\left(20, \phi_{i r 3}\right)$, where $\phi_{i r 2}$ and $\phi_{i r 3}$ are binomial parameters used to specify probabilities of individual numbers of victims. The binomial distributions are used to express the analyst's uncertainty in the numbers of fire victims. Values of $\phi_{i r 2}$ and $\phi_{i r 3}$ are given in Table 2. Figure 3 illustrates the distribution of the random significance $\tilde{s}_{123} \sim B\left(20, \phi_{123}\right)$.

The durations of outage are also treated as random quantities and modelled by the random variables $\tilde{s}_{i r 4}$. The analyst's uncertainty in the outage duration is expressed by means of Poisson distribution, namely, $\tilde{s}_{i r 4} \sim P\left(\lambda_{i r}\right)$. Values of $\lambda_{i r}$ related to individual alternatives and fire scenarios are given in Table 2. Figure 4 shows the probability mass function for the uncertain outage $\tilde{s}_{114} \sim P\left(\lambda_{14}\right)$.

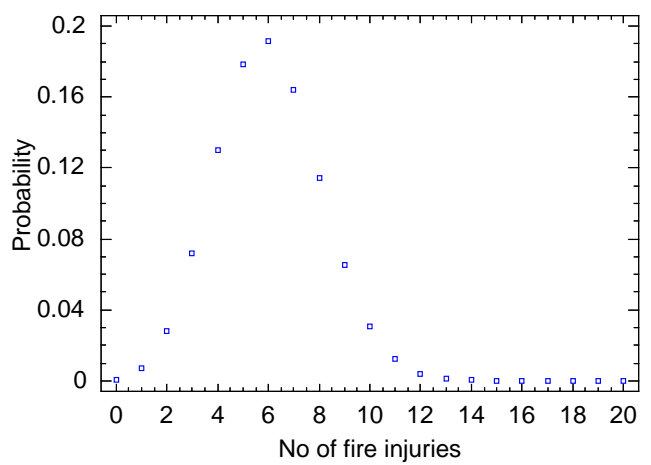

Figure 3. Probability mass function of the random number of injured persons, $\tilde{s}_{123}$ (sprinkler system $a_{1}$, fire scenario $\left.r=2\right) ; \tilde{s}_{123} \sim \mathrm{B}(20,0.3)$ 


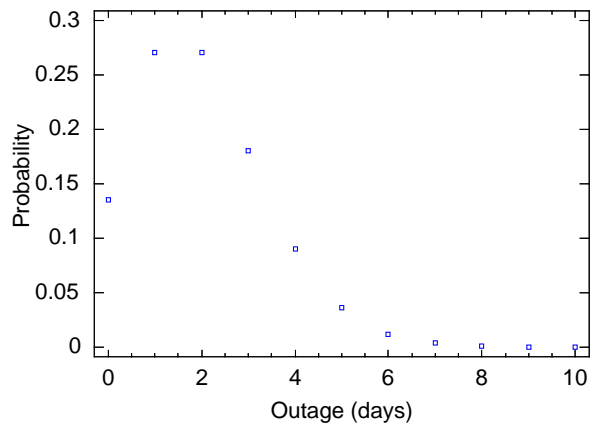

Figure 4. Probability mass function of the random duration of outage, $\tilde{s}_{114}$ (sprinkler system $a_{1}$, fire scenario $r=1) ; \tilde{s}_{114} \sim P(2.0)$
With the random vectors $\tilde{\boldsymbol{s}}_{i r}$ and the random likelihoods $L_{i r}$, the attribute vector $\mathrm{c}_{i}$ becomes a vector with four random and one fixed components:

$$
\begin{aligned}
& \tilde{\boldsymbol{c}}_{i}=\left(\tilde{c}_{i 1}, \tilde{c}_{i 2}, \tilde{c}_{i 3}, \tilde{c}_{i 4}, c_{i 5}\right)= \\
& =\left(\sum_{r=1}^{4} L_{i r} \tilde{s}_{i r 1}, \sum_{r=1}^{4} L_{i r} \tilde{s}_{i r 2}, \sum_{r=1}^{4} L_{i r} \tilde{s}_{i r 3},\right. \\
& \left.\sum_{r=1}^{4} L_{i r} \tilde{s}_{i r 4}, c_{i 5}\right)
\end{aligned}
$$

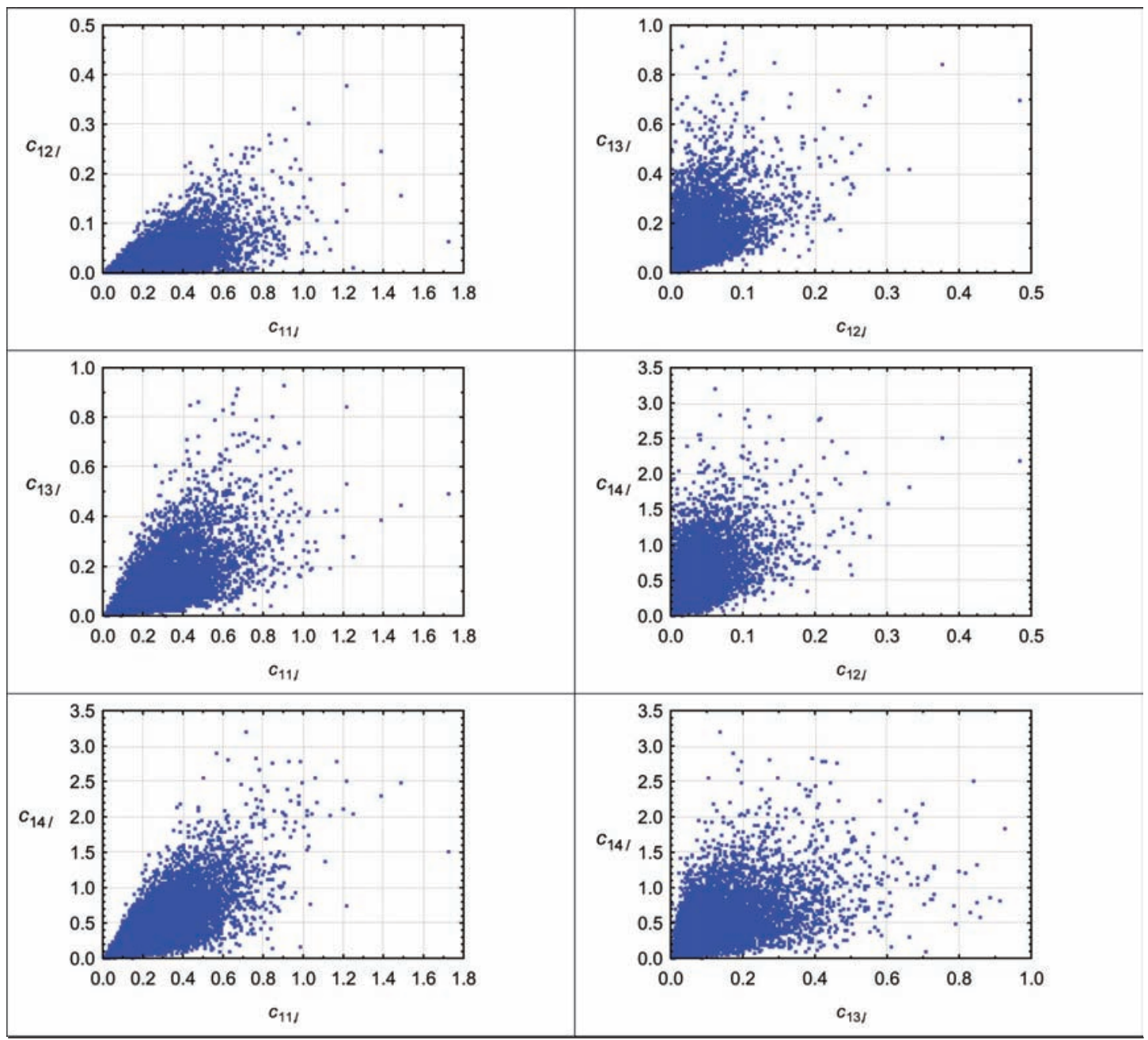

Figure 5. Scatter diagrams drawn for pairs of the simulated values $\tilde{c}_{11, l}, \tilde{c}_{12, l}, \tilde{c}_{13, l}$, and $\tilde{c}_{14, l}$ of the components of the random decision matrix $\tilde{\mathbf{C}}(l=1,2, \ldots, 10000)$ 
The random components of $\tilde{\boldsymbol{c}}_{i}$ are expected significances.

The vectors $\tilde{c}_{i}$ defined by Eq. (11) form a $3 \times 5$ stochastic decision matrix $\tilde{\mathbf{C}}=\left[\tilde{\boldsymbol{c}}_{1}, \tilde{\boldsymbol{c}}_{2}, \tilde{\boldsymbol{c}}_{3}\right]^{\mathrm{T}}$. The selection of $a^{*}$ with $\tilde{\mathbf{C}}$ is based on sampling the matrices $\tilde{\mathbf{C}}_{l}$.

Components of $\tilde{\boldsymbol{c}}_{i}$ are functions of common random variables and so they are stochastically dependent, a practical implementation of sampling of $\tilde{\mathbf{C}}_{l}$ is problematic. However, the components of $\tilde{\boldsymbol{c}}_{i}$ are represented by relatively simple Eqs. (10) and (11), in which the random variables $L_{0}, \tilde{p}_{1}$ and $\tilde{p}_{i 2}$ as well as components of $\tilde{\boldsymbol{s}}_{i r}$ can be assumed to be independent. Therefore the sampling from joint probability distributions of $\tilde{\boldsymbol{c}}_{i}$ can be replaced by a simpler sampling from epistemic distributions of $L_{0}, \tilde{p}_{1}$ and $\tilde{p}_{i 2}$ as well as distributions of the components of the vectors $\tilde{\boldsymbol{s}}_{i r}$ and calculating values of $\tilde{\boldsymbol{c}}_{i}$ by means of Eqs. (10) and (11).
Results of such a sampling are illustrated for the vector $\tilde{\boldsymbol{c}}_{1}$ in Figure. 4 and 5.

For each sampled value $\tilde{\mathbf{C}}_{l}$, a value of the normalized decision matrix $\overline{\mathbf{C}}_{l}$ was calculated using the vector normalization formula:

$$
N M: \quad \bar{c}_{i j}=\tilde{c}_{i j l} /\left(\sum_{i=1}^{m} \tilde{c}_{i j}^{2}\right)^{-1 / 2}
$$

where: $\tilde{c}_{i j l}$ is the value of the random component $\tilde{c}_{i j}$ of $\tilde{\mathbf{C}}$ sampled in the simulation step $l$. The MAS criteria $K_{1}$ to $K_{3}$ presented in Table 3 were applied to $\overline{\mathbf{C}}_{l}$ with the weights:

$$
\boldsymbol{w}=(0.20,0.30,0.25,0.10,0.15)^{\mathrm{T}}
$$

The components of $\boldsymbol{w}$ mean that the greatest significance was assigned to the attributes associated with the possible harm to people. The above weights have been chosen only as an example.

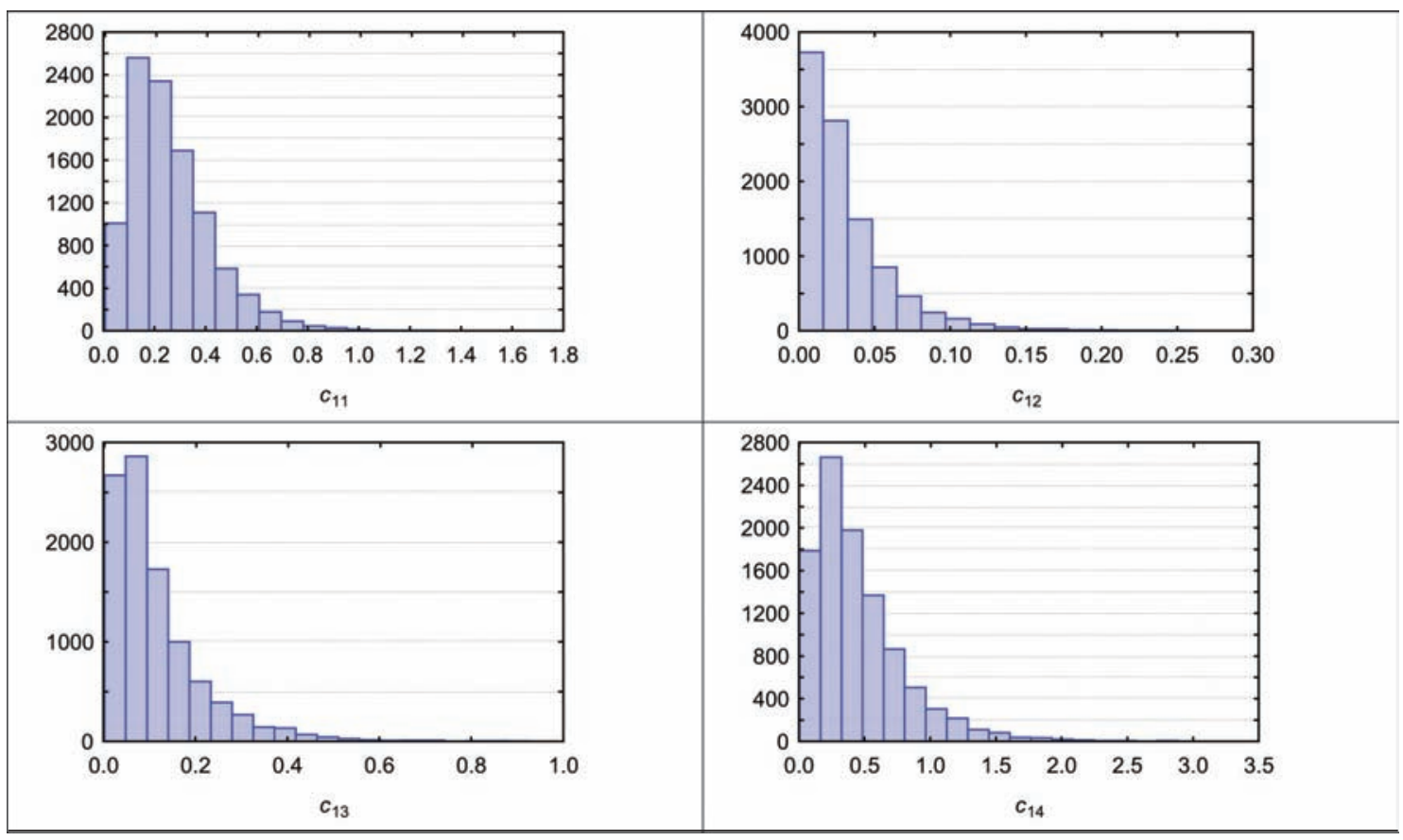

Figure 6. Histograms drawn for the simulated values $\tilde{c}_{11, l}, \tilde{c}_{12, l}, \tilde{c}_{13, l}$, and $\tilde{c}_{14, l}$ of the components of the random decision matrix $\tilde{\mathbf{C}}(l=1,2, \ldots, 10000$; the vertical axes in these graphs indicate the number of observations) 
A total of $1 \times 10^{4}$ simulation steps were carried out to propagate the epistemic uncertainty in $l_{0}, p_{1}$, and $p_{i 2}$ and components of $\tilde{\boldsymbol{s}}_{i r}$ through the expressions (10) and (11) and then through the expressions of the criteria $K_{1}$ to $K_{3}$ given in Table $3\left(N_{l}=1 \times 10^{4}\right)$.

In each step, $K_{1}$ to $K_{3}$ were used to find the best sprinklers $a^{*}$ on the basis of $\tilde{\mathbf{C}}_{l}$. The simulation yielded the frequencies $f r_{i}$ given in Table 3. All three criteria $K_{1} K_{2}$ and $K_{3}$ suggest $a_{3}$ as $a^{*}$.

Results obtained in this example are dependent on the vector normalization formula (12) used together with the criteria $K_{1}$ to $K_{3}$. An application of other normalization formula may lead to different results of MAS. Therefore, results of MAS are conditioned on the use of specific normalization formula.

\section{CONCLUSIONS}

The design of fire safety of buildings by applying formal means of multi-attribute selection (MAS) has been considered. Such a design requires to compare alternative solutions of fire safety provisions in a building. In case where the choice of an optimal solution is carried out in line with the performance-based fire design, the attributes of an MAS problem must include measures of fire safety.

The prevailing approaches to fire safety assessment today are fire risk indexing and estimation of fire risk used for quantitative risk assessment (QRA). Fire risk indices are popular and easy to implement systems of fire safety evaluation. However, their use within MAS is problematic, because the indices may be not sufficiently sensitive to differences among alternative fire design solutions, for instance, alternative systems of automatic sprinklers. In addition, there exists large number of indices which are used in different countries and regions and are barely compatible with each other. The development of procedures used for the calculation of fire indices is not sufficiently documented and the calculation itself has a high degree of subjectivity.

An estimation of fire risk in line with QRA is carried out by applying much more rigorous procedures than those used for calculation of fire risk indices. Estimates of fire risk can be incorporated into a MAS problem by calculating expected severities related to individual outcomes (scenarios) of fire disaster. The fire risk can be related to alternative fire design solutions by estimating reliabilities (failure probabilities) of fire protection measures provided by individual designs.

The estimation of failure probabilities of fire protection measures in particular and fire risk in general can be a non-trivial task. The solution of it may require failure rate data and elicitation of expert opinions. However, the fire risk is a very comprehensive measure of fire safety and its estimation is worth of effort, especially if the fire design is carried out in line with the performance-based design codes.

The estimation of fire risk in line with QRA may lead to the result that some or all elements of risk will be uncertain in the epistemic sense. An incorporation of probability distributions expressing the epistemic uncertainty into an MAS problem will lead to a composition of a random decision matrix. The MAS problem with such a matrix can be solved by propagating the uncertainties through MAS models. This can be done by embedding these models into the loop of a Monte Carlo simulation. Such a propagation is illustrated in the text by an example of a choice among alternative systems of fire sprinklers.

\section{REFERENCES}

Aven, T. (2003) Foundations of risk analysis: a knowledge and decision-oriented perspective. Chichester: Wiley.

Aven, T. and Pörn, K. (1998) Expressing and interpreting the results of quantitative risk analyses. Review and discussion, Reliability Engineering \& System Safety, 61(1-2), pp. 3-10. doi:10.1016/S0951-8320(97)00060-4 
Bradyberry, M. D. and Apostolakis G. E. (1991) Fire risk in buildings: frequency of exposure and physical model, Fire Safety Journal, 17(5), pp. 339-361. doi:10.1016/0379-7112(91)90017-S

Brown, H. (2005) Economic analysis of residential fire sprinkler systems, NISIR 7277. Gaithersburg: National Institute of Standards and Technology.

Butry, D. T., Brwon, M. H. and Fuller, S. K. (2007) Benefit-cost analysis of residential fire sprinkler systems. NISTIR 7451. Gaithersburg, MD: National Institute of Standards and Technology.

Craighead, G. (2009) High-rise security and fire life safety, $3^{\text {rd }}$ Edition. Amsterdam: Elsevier.

Donegan, H. A. (2002) Decision analysis. In: SFPE Handbook of fire protection engineering, $5^{\text {th }}$ Edition. NFPA \& SFPE, Quincy, MA, pp. 5-8 $-5-23$.

Figueira, J., Greco, S. and Ehrgott, M., eds. (2005) Multiple criteria decision analysis: State of the art surveys. Berlin: Springer.

FRAME (2010) Fire risk assessment method for engineering. [Online] Available at: <http://www. framemethod.net/>.

French, S. (1988) Decision theory: an introduction to the mathematics of rationality. Ellis Harwood \& Wiley, Chichester \& New York.

Guanquan, C. and Jinhua, S. (2008) Quantitative assessment of building fire risk to life safety, Risk Analysis, 28(3), pp. 615-625. doi:10.1111/j.1539-6924.2008.01048.x

Hall, J. R. (2010) U.S. Experience with sprinklers and other other fire extinguishing equipment. National Fire Protection Association.

Hasofer, A. M., Beck, V. R. and Bennetts, I. D. (2007) Risk analysis in building fire safety engineering. Amsterdam: Butterworth \& Heinermann.

Hauptmanns, U., Marx, M. and Grünbeck, S. (2008) Availability analysis for a fixed wet sprinkler system, Fire Safety Journal, 43(7), pp. 468476. doi:10.1016/j.firesaf.2008.03.002

Helton, J. C. and Oberkampf, W. L. (2004) Alternative representations of epistemic uncertainty, $R e$ liability Engineering \& System Safety, 85(1-3), pp. 1-10. doi:10.1016/j.ress.2004.03.001

Hoła, B. (2006) Development tendency of accident situation in building construction, Archives of Civil and Mechanical Engineering, 6(3), pp. 81-93.
Hoła, B. (2007) General model of accident rate growth in the construction industry, Journal of Civil Engineering and Management, 13(4), pp. 255-264.

Hoła, B. (2009a) Dynamics of the development of accident situation in construction industry with reference to building production value, Archives of Civil Engineering, 55(2), pp. 151-171.

Hoła, B. (2009b) Methodology of estimation of accident situation in building industry, Archives of Civil and Mechanical Engineering, 9(1), pp. $29-46$.

Hoła, B. (2010) Methodology of hazards identification in construction work course, Journal of Civil Engineering and Management, 16(4), pp. 577-585.

Hoła, B. and Schabowicz, K. (2010) Estimation of earthworks execution time cost by means of artificial neural networks, Automation in Construction, 19(5), pp. 570-579.

Hwang, C. L. and Yoon, K. S. (1981) Multiple decision making methods and applications, Lecture Notes in Economics and Mathematical Systems, 186, Berlin: Springer.

Kirchsteiger, Ch., Christou, M. D. and Papadakis, G. A. (1998) Risk assessment and management in the context of the Sevelso II directive. Amsterdam: Elsevier.

Kumamoto, H. and Henley, E. J. (1996) Probabilistic risk assessment and management for engineers and scientists, $2^{\text {nd }}$ Edition. New York: IEEE Press.

Lai, C., Su, H.-C., Tsai, M.-J., Chen, C.J., Tzeng, C.-T. and Lin, T.-H. (2010) Influence of fire source locations on the actuation of wet-type sprinklers in an office fire, Building and Environment, 45(1), pp. 107-114. doi:10.1016/j.buildenv.2009.05.007

Liu, P. (2009) Multi-attribute decision-making method research based on interval vague set and TOPSIS method, Technological and Economic Development of Economy, 15(3), pp. 453463. doi:10.3846/1392-8619.2009.15.453-463

Meacham, B. J. (2002) Building fire risk analysis. In: SFPE Handbook of fire protection engineering, $5^{\text {th }}$ Edition. NFPA \& SFPE, Quincy, MA, pp. 5-153-5-175.

Natorianni, (2002) Uncertainty. In: SFPE Handbook of fire protection engineering, $5^{\text {th }}$ Edition. NFPA \& SFPE, Quincy, MA, pp. 5-41-5-64. 
NFPA (2009) Guide for the evaluation of fire risk assessments, 2010 edition. National Fire Protection Association, Quincy, MA.

Nyyssönen, T., Rajakko, J. and Keski-Rahkonen, O. (2005) On the reliability of fire detection and alarm systems. Exploration and analysis of data from nuclear and non-nuclear installations. Finland: VTT Building and Transport.

Peldschus, F. (2009) The analysis of the quality of the results obtained with the methods of multicriteria decisions, Technological and Economic Development of Economy, 15(4), pp. 580-592. doi:10.3846/1392-8619.2009.15.580-592

Ramachandran, G. (1998) The economics of fire protection. London: E \& FN Spon. doi:10.4324/9780203476123

Ramachandran, G. (2002) Measuring fire consequences in economic terms. In: SFPE Handbook of Fire Protection Engineering, $5^{\text {th }}$ Edition. NFPA \& SFPE, Quincy, MA, pp. 5-79 - 5-92.

Rasbash, D. J., Ramachandran, G., Kandola, B., Watts, J. M. and Law, M. (2004) Evaluation of fire safety. Chichester: Wiley. doi:10.1002/0470020083

Rönty, V., Keski-Rahkonen, O. and Hassinen, J. P. (2004) Reliability of sprinkler systems. Exploration and analysis of data from nuclear and non-nuclear installations. Finland: VTT Building Technology.

Sakalauskas, L. and Zavadskas, E. K. (2009) Optimization and intelligent decisions, Technological and Economic Development of Economy, 15(2), pp. 189-196.

doi:10.3846/1392-8619.2009.15.189-196

Šakènaite, J., and Vaidogas, E. R. (2010) Fire risk indexing and fire risk assessment: a comparison of pros and cons. In: Vainiūnas, P. and Zavadskas, E. K. (eds.), Proceedings of the $10^{\text {th }}$ international conference on modern building materials structures and techniques, 19-21 May 2010, Vilnius, Lithuania. Vilnius: Technika, Vol. II, pp. 1297-1305.

Schabowicz, K. and Hola, B. (2007) Mathematicalneural model for assessing productivity of earthmoving machinery, Journal of Civil Engineering and Management, 13(1), pp. 47-54.

SFPE (2006) Engineering guide to fire risk assessment. Society of Fire Protection Engineers, Bethesda, MD.

Siu, N. and Apostolakis, G. (1988) Uncertain data and expert opinions in the assessment of the unavailability of suppression systems, Fire Technology, 24(2), pp. 138-162.

doi:10.1007/BF01041339

Smith, D. J. (2005) Reliability, maintainability, and risk. practical methods for engineers, $7^{\text {th }}$ Edition. Amsterdam: Elsevier.

Triantaphyllou, E. (2000) Multi-criteria decision making methods: a comparative study. Series Applied Optimization, 44, Kluwer Academic Publishers, Dordrecht etc.

Urbanavičienè, V., Kaklauskas, A., Zavadskas, E. K. and Seniut, M. (2009) The web-based real estate multiple criteria negotiation decision support system: a new generation of decision support systems, International Journal of Strategic Property Management, 13(3), pp. 267-286. doi:10.3846/1648-715X.2009.13.267-286

Vaidogas, E. R. (2003) Accidental explosions: Bayesian uncertainty handling in assessing damage to structures. In: Der Kiureghian, A., Madanat, S. and Pestana, J. M. (eds.), Proceedings of the $9^{\text {th }}$ international conference on applications of statistics and probability in civil engineering, 6-9 July 2003, San Francisco, CA., Rotterdam: Milpress Science Publishers, Vol. 1, pp. 191198.

Vaidogas, E. R. (2006) First step towards preventing losses due to mechanical damage from abnormal actions: knowledge-based forecasting the actions, Journal of Loss Prevention in the Process Industries, 19(5), pp. 375-385. doi:10.1016/j.jlp.2005.10.002

Vaidogas, E. R. (2007) Risk oriented design of protective highway structures, The Baltic Journal of Road and Bridge Engineering, 2(4), pp. 155-163.

Vaidogas, E. R. and Hayashi, H. (2007) Multi-attribute selection from alternative designs of a protective structure in the presence of epistemic uncertainty in the failure-to-protect probability. In: Kanda, J., Takada, T. and Furuta, $\mathrm{H}$. (eds.), Proceedings on $C D$ of the $10^{\text {th }}$ international conference on applications of statistics and probability in civil engineering (ICASP10), 31 July -3 August 2007, Tokyo, Japan. London: Taylor \& Francis.

Vaidogas, E. R. (2009) On applying sparse and uncertain information to estimating the probability of failure due to rare abnormal situations, Information Technology and Control, 38(2), pp. 135-146. 
Vaidogas, E. R. and Juocevičius, V. (2007) Assessing external threats to structures using limited statistical data: an approach based on data resampling, Technological and Economic Development of Economy, 13(2), pp. 170-175.

Vaidogas, E. R. and Juocevičius, V. (2008a) Sustainable development and major industrial accidents: the beneficial role of risk-oriented structural engineering, Technological and Economic Development of Economy, 14(4), pp. 612-627. doi:10.3846/1392-8619.2008.14.612-627

Vaidogas, E. R. and Juocevičius, V. (2008b) Reliability of a timber structure exposed to fire: estimation using fragility function, Mechanika, (5), pp. 35-42.

Vaidogas, E. R. and Juocevičius, V. (2009) Assessment of structures subjected to accidental actions using crisp and uncertain fragility functions, Journal of Civil Engineering and Management, 15(1), pp. 95-104. doi:10.3846/1392-3730.2009.15.95-104

Vaurio, J. K. and Jänkälä, K. E. (2006) Evaluation and comparison of estimation methods for failure rates and probabilities, Reliability Engineering \& System Safety, 91(2), pp. 209-221. doi:10.1016/j.ress.2005.01.001

Watts, J. M. (2002) Fire risk indexing. In: SFPE Handbook of fire protection engineering, $5^{\text {th }}$ Edition. NFPA \& SFPE, Quincy, MA, pp. 5-125-5-142.

Watts, J. M. and Kaplan, M. E. (2001) Fire risk index for historic buildings, Fire Technology, 37(2), pp. 167-180. doi:10.1023/A:1011649802894

Watts, J. M. and Solomon, R. E. (2002) Fire safety code for historic structures, Fire Technology, 38(4), pp. 301-310. doi:10.1023/A:1020110214065

Yung, D. (2008) Principles of fire risk assessment in buildings. Chichester: Wiley. doi:10.1002/9780470714065

Zavadskas, E. K., Kaklauskas, A., Turskis, Z. and Tamošaitienè, J. (2008) Selection of the effective dwelling house walls by applying attributes values determined at intervals, Journal of Civil Engineering and Management, 14(2), pp. 85-93. doi:10.3846/1392-3730.2008.14.3

Zavadskas, E. K. and Vaidogas, E. R. (2009) Multiattribute selection from alternative designs of infrastructure components for accidental situations, Computer-Aided Civil and Infrastructure Engineering, 24(5), pp. 346-358. doi:10.1111/j.1467-8667.2009.00593.x

Zhao, C. M., Lo, S. M., Lu, J. A. and Fang, Z. (2004) A simulation approach for ranking of fire safety attributes of existing buildings, Fire Safety Journal, 39(7), pp. 557-579. doi:10.1016/j.firesaf.2004.06.001

\section{SANTRAUKA}

\section{STATYBINIO TURTO GAISRINĖS SAUGOS UŽTIKRINIMAS: DAUGIAKRITERINIS SPRENDIMŲ PRIĖMIMAS ATSIŽVELGIANT I GAISRO RIZIKĄ}

\section{Egidijus Rytas VAIDOGAS, Jurgita ŠAKĖNAITE்}

Norint užtikrinti pastatų gaisrinę sauga, gali prireikti lyginti alternatyvius projektinius saugos sprendimus. Tai atlikti galima pasitelkiant daugiakriterinio vertinimo metodologija. Alternatyvieji sprendimai gali būti aprašyti keletu charakteristiku (atributu) ir lyginami vienas su kitu. Straipsnyje atributu sąrašas sudaromas naudojant gaisro rizikos išraiška, sudaromą kiekybinio rizikos vertinimo principais. Parodyta, kaip atlikti daugiakriterini vertinima, kai rizikos išraiškos elementai yra neapibrèžti epistemine prasme. Episteminio neapibrěžtumo skirstiniai priskiriami uždavinio atributams ir propaguojami matematiniais daugiakriterinio vertinimo modeliais pasitelkiant Monte Karlo modeliavimą. Pateikiamas pavyzdys, nagrinèjantis automatinių sprinkleriu sistemos parinkimą iš kelių alternatyvių variantų. 